\section{Re-thinking gig economy in conventional workforce post-COVID-19: a blended approach for upholding fair balance}

\author{
Manjari Mahato, Nitish Kumar and Lalatendu Kesari Jena \\ School of Human Resource Management, XIM University, Bhubaneswar, India
}

\begin{abstract}
Purpose - Despite the trend, managing and maximizing the effectiveness of blended workforce is not wellunderstood. The purpose of this paper is to institutionalize a blended workforce model in the post-COVID era, that is, a movement from homogenous workforce to heterogenous workforce of full-time employees working in tandem with gig talents connected via digital platforms.

Design/methodology/approach - The evolution of gig economy is presented for contextualizing the development of prospective business models in the post-COVID era to establish clarity on the relationship between the employers and the blended workforce. To achieve this conceptual switch, a framework is proposed to support this type of workforce for creating a fair balance.

Findings - By drawing on the concepts of various talent management functions, propositions were made predicting that the alignment of the multilateral activities of the gig workers with permanent workforce will be leveraged in the future to address the needs of short-term specialized skill-sets and scalable operations while creating a fair balance through a flexible and agile workforce.

Originality/value - First, the paper explores how bridging the gap between the traditional and gig workforce can impact the key antecedents of a blended workforce ensuring a fair trial. Second, on an economical level, the COOKIE framework proposed in the paper is expected to play a crucial role in creating new job opportunities, boosting employee morale while minimizing costs and increasing productivity of the organizations.
\end{abstract}

Keywords Collaboration, Openness, Opportunity, Knowledge, Fair balance, Blended workforce

Paper type Conceptual paper

\section{Introduction}

"One thing everyone is fairly confident of is that roles in the future will be different. We are going to have a blended workforce", Paul Surridge, Leadership Consulting Partner, UK stresses on the emerging trend of modern workplace which will comprise of a blended [1] workforce post-COVID era with rising confidence on remote working and expansion of on-demand jobs. The pandemic's impact will likely result in a meaningful collaboration between full-time workers and independent contributors, which will eventually provide firms an opportunity to hire talented pinch hitters for tasks without allocating a significant amount towards salaries and incentives, thus giving rise to a unique workplace milieu: gig economy (Knowledge@ Wharton, 2020).

(C) Manjari Mahato, Nitish Kumar and Lalatendu Kesari Jena. Published in Journal of Work-Applied Management. Published by Emerald Publishing Limited. This article is published under the Creative Commons Attribution (CC BY 4.0) licence. Anyone may reproduce, distribute, translate and create derivative works of this article (for both commercial and non-commercial purposes), subject to full attribution to the original publication and authors. The full terms of this licence may be seen at http:// creativecommons.org/licences/by/4.0/legalcode

The authors are thankful to XIM University Bhubaneswar, India and Dean, School of Human Resource Management, XIM University, Bhubaneswar, India for supporting this research.
Gig economy in conventional

workforce 
JWAM

13,2

262

The origin of the term "gig" can be traced back to the 1920s, when Jazz performances were gaining nationwide popularity in the US. These musical acts were single occasion, fixed time activities which led to the concept of gig jobs, whereby participants have flexible work options sans benefits of employment (Whitehead, 2019). However, there is no universal interpretation of gig work till date. Depending on various studies, we can closely define it as a need-based or assignment-based task comprising of interactions among multiple parties, usually involving a seller, a buyer and a platform (a digital element between the buyer and seller), where the seller is the groom, the buyer is the bride and the platform acts as the matchmaker (Healy et al., 2017). Other characteristics of the gig economy include flexible working patterns based on servicebased demand and workers having the liberty to choose their own place of work with tasks being performed over an online platform (Stewart and Standford, 2017). This absence of a continuous work relationship makes the gig workers' work schedules and earnings unpredictable. This also reflects an absence of any pre-defined progression or capability development for the concerned workers (Abraham et al., 2019; Johnes, 2019).

The current uncertainty in traditional employment relationships arising due to the ongoing pandemic implicates further consideration for organizations to expand the share of gig workers post-COVID 19 to achieve agility in scaling their workforce up and down as per the business needs. The blended model embodies a new mode of assignment or need-based hiring, wherein organizations engage independent workers with the full-time employees to create a team via various platforms (Jabagi et al., 2019). Drawing on this approach, this conceptual paper explores how bridging the gap between the traditional and gig workforce can impact the key antecedents of a blended workforce ensuring a fair trial.

The above context lays the foundation of this research paper. First, the need of a blended workforce in the modern workplace (including origin, key definition and overview of market size) is introduced. Next, the evolution of gig economy is presented in order to contextualize the development of prospective business models in the post-COVID era to establish clarity on the relationship between the employers and the blended workforce. To achieve this conceptual switch, a framework model is proposed to support this type of workforce for creating a fair balance. The paper concludes with the theoretical, practical and societal implications of the model and, finally, stresses on the need of further inquiry for pervasion of gig economy in the new normal.

\section{Gig economy and emerging business models}

Evolution of gig economy

"Gig" jobs have existed for many years and its evolution can be traced since the pre-industrial era. Consider, for example, during the 18th century in Europe, when guild system defined standards in disparate trades like textile, clothing, footwear, cutlery, small furnishings and other simple consumer goods, a merchant delegated production tasks to employees who performed work in their own homes using their own equipment. The output of their labour was owned by the merchant capitalist who supplied the initial raw materials and supplies while the producers merely performed incremental value-adding labour on those materials. These independent workers were paid by the piece and were not necessarily guaranteed any re-engagement to perform similar tasks as well as any fixed number of paid weekly hours at a given hourly rate (Stanford, 2017; Chappe and Jaramillo, 2020). This piece-rate work system encouraged productivity and time-efficiency among the workers in comparison to fixed wages as this type of work induced higher level of effort (Tanski-Phillips, 2018; Borino, 2018).

The gradual shift from the guild system towards industrial work saw a continued dominance of this piece rate pay method (wherein, a worker is paid according to the number of units produced rather than the time spent on the job) among the middle-income workers, especially in the garment factories as well as other manufacturing and production industries 
(Borino, 2018; Reddy, 2016; Brunelli, 2019). During the 1980s, conventional organizations started adopting more flexible short-term jobs as compared to full-time employment offers. As part of restructuring, on-demand labour such as management consultants and temp agencies facilitated the work via cyclical replacement. By 1988, almost nine-tenth of businesses was using temporary labour to some extent (Hyman, 2018).

Given these high valuations, economic historian Louis Hyman (2018) identified that with every economic downturn since 1991, the number of gig workers increased to address job losses in the low-skilled labour market. During the brink of Great Recession, Tina Brown, journalist, was first to coin the term "gig economy" in 2009. She wrote about the trend of workers pursuing "a bunch of free-floating projects, consultancies and part-time bits and pieces while they transacted in a digital marketplace". Simultaneously, with the advent of technological advancements in Industry 4.0, companies began virtually balancing between archaic full-time workforce model and gig workforce model.

These firms can benefit from a blended economy since it brings together the essence of both worlds - autonomy and independence of gig workers along with the steadiness and psychological relief of full-time employees. Considering the importance of this blended workforce post-COVID era, the next section introduces the emerging business model that is increasingly being adopted by companies with the ever-changing relationship between employers and the blended team.

\section{Emerging business model in the COVID-19 era}

The COVID-19 pandemic is rapidly expanding across the globe with multiple existing challenges such as health problems, rapid population growth and increased movement of people (Nkengasong and Mankoula, 2020). In such times, the application of Industry 5.0 such as digitalization coupled with hyper-personalization [2] could shape a business model to provide revenue via digital business making these businesses more evident. And rightly so, this has forced many businesses to re-think their way of functioning and necessitated the demand to move from offline to online $(\mathrm{O} 2 \mathrm{O})$, thus paving the way for more short-term jobs through third party web based and mobile platforms. As outlined by Healy et al. (2017), these platforms are proprietary applications (apps) which users download and use. This facilitates the formation of a triangular relationship, a novel business concept, where producers and end users can exchange goods/services with the help of the digital intermediary (Stewart and Stanford, 2017). In this sense, the platform economy is different from other forms of contract work, where the transactions can be mediated offline or online, and can cross international borders.

This concept has led to the emergence of various work intermediation models such as online staffing platforms, online work services and crowdsourcing, thus enabling work arrangements of various kinds to be established entirely through a digital/online platform. SIA (2018) states that online staffing platforms establish a direct labour relationship by matching workers of different skillsets, geolocations, etc. with businesses or individuals looking for project-based workers or hourly workers (local or remote). It also defines another sub-segment of the online platform model, online work services, that enables gig workers to provide "service output" (not a labour relationship) to the companies or consumers that raise a "service request" via the online medium. The other online work intermediation model, i.e. crowdsourcing model, consists of two categories: first, distributed micro-task model, wherein a project is broken into micro-tasks and completed by a group of workers who perform at their own will, and later on combine the completed tasks to deliver the finished project and second, contest-based model, wherein a challenge is posted to the platform which is then solved and submitted by the workers and the best solution gets awarded in this contest-based model (SIA, 2018). Figure 1 presents these talent exchange platforms and lists down various organizations that support the enactment and management of work under these models. It is important to note that some of the organizations use a mix of two models to facilitate their transactions.
Gig economy in conventional workforce 


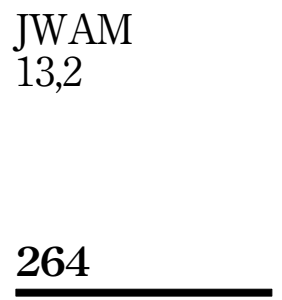

Figure 1.

Talent exchange platforms to support work arrangements

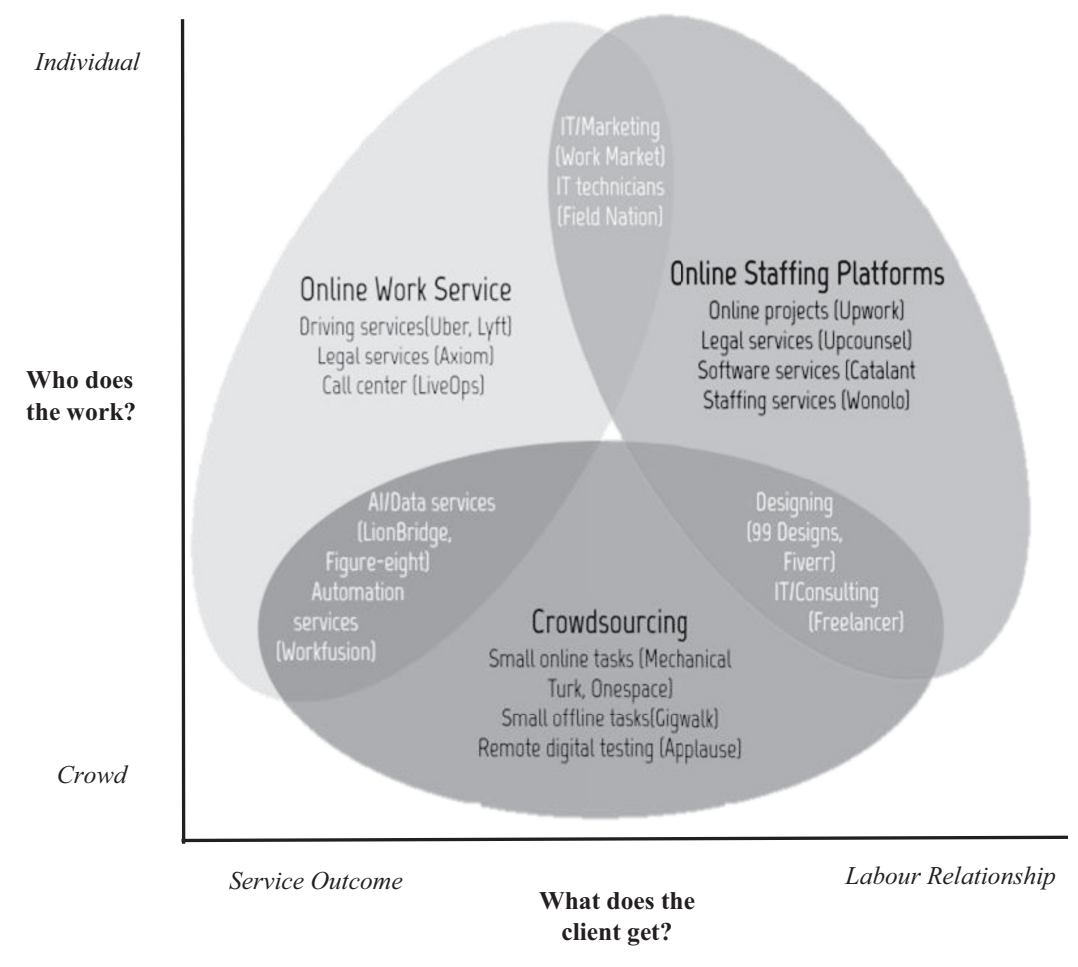

The triangular relationship exhibited by these work models is also the main source of complication between the parties involved. Retaining control of working volume and working conditions by the intermediary platforms, risk involved with the precarious nature of work along with occupational vulnerabilities for the service providers and skewness in the contract between intermediary and service provider makes it biased and unclear (Scheiber, 2017; Healy et al., 2017). In place of maintaining staff consisting almost entirely of employees with permanent full-time jobs (forming a huge expense in terms of companies' income and turnover) or gig workers, our research paper proposes an integrated framework of talent management cycle (TMC) (excluding recruitment and separation) for a blended workforce that incorporates a fair proportion of both full-time employees and gig workers.

\section{Blended workforce framework from a talent management perspective}

To further our theoretical development on the integrated framework, we first need to understand the talent management strategies for the full-time employees and the gig workforce. The strategies are mainly dependent on the employee perception or "psychological contract" which can be introduced in two distinctive forms in employment relations, namely, the transactional psychological contract (short-term and includes economic, monetary or materialistic emphasis on individuals' reciprocal exchange agreement with their employers) and the relational psychological contract (long-term and includes socio-emotional exchanges, mutual trust and loyalty, such as job security and career development) (Savarimuthu and Rachel, 2017). Studies indicate that psychological contract fulfillment can increase task performance for all gig workers, regardless of their tenure in the company (Liu et al., 2020). 
In an increasingly fissured work environment, such a positive employee perception can influence the overall performance of a blended workforce. Basic functions such as collaboration, performance management, learning and development, rewards and recognition, career and succession planning, and whether the individual is organization-fit or not have become increasingly important, forcing organizations to contemplate their talent management strategies post-COVID-19.

\section{Collaboration}

Essentially, organized team work increases productivity of any business, making collaboration between full-time workers as the key factor in a company's success. It presents an opportunity for all team members to brainstorm their ideas and ask questions to improve effective communication (group brainstorming) (Paulas and Kenworthy, 2019). When individuals from different verticals get involved, it leads to the genesis of fresh ideas and diverse perspectives (cross-functional collaboration). These diverse viewpoints make problem-solving easier and faster, thus inviting in-house innovation to expedite the implementation of solutions (Elikwu, 2019). Slack, WebEx, etc. serve as the right platforms among these teams to collaborate effectively. Same or similar platforms are also leveraged by gig workers to communicate (formal or informal conversations) in a virtual workspace. Such platforms assist them in maintaining awareness of their collaborators (Morrison-Smith and Ruiz, 2020). The cloud technology further enhances the growth of these online collaboration portals making it easier for the workers to connect from any location (cloud-based platform). The ad hoc development of discussion communities (gig discussion communities) facilitates shared leadership by the socially related exchange of information that creates commitment, trust and cohesion among the members (Morrison-Smith and Ruiz, 2020). It presents opportunities for companies to listen to the best ideas proposed, via open calls, for the execution of the company business (Ruggieri et al., 2016).

When we expand our understanding in context of the discussed workforces, we find that control and trust are the two determinants to measure collaboration that often fails due to ineffective management of the globally distributed workforce. In the current scenario of uncertainty, organizations have started reconsidering their management practices by taking steps like employee tracking to monitor their employees for better collaboration and setting up emergency notification systems to maintain data security (EY, 2020). This planning poses a question for the entire business community, that is, for how long these temporary solutions will continue to exist? Rajesh Gopinathan, CEO of India's largest IT company, TCS, stated in the FY'20 Annual Report of the company that "by 2025, only 25\% of our associates will need to work out of our facilities at any point of time; every associate will be able to realize their potential without spending more than 25\% of their time in a TCS office" (Financial Express, 2020). These advancements have led us to propose a blended workforce framework, where a potential digital collaboration of different perspectives can exist between gig economy workers and full-time employees in a single team.

Enterprise networks can be particularly valuable from collaboration perspective in a blended team. Personalized activity streams, via platforms displaying the designation, experience and skillset of full-time employees as well as the distributed expertise (projects undertaken and skillset) of gig workers, can act as a medium for instrumental support among these workers. Project related updates like new client requirements, cross-functional developments and task lists can be used as a repository of information to confirm their abilities to perform work. Team chats have a crucial role to play in enabling digital collaboration among the blended teams to create an environment that supports their collective team goals but also harnesses their individual creativity bringing economic value to the organizations. It further implies that there is a requirement of open brainstorming clubs

Gig economy in conventional workforce 
JWAM

13,2

\section{6}

to promote the blended culture. Therefore, it is proposed that integration of platforms within enterprise networking, where the co-workers are connected with each other as well as the organization, can support perceived social inclusivity:

P1. A blended workforce can bring in social inclusivity by combining internal (group or cross-functional) collaboration dominant in the full-time workforce with the cloudbased collaboration platforms relevant for gig workers.

Performance management

According to UC Berkeley HR (2020), performance management is "an ongoing process of communication between a supervisor and an employee that occurs throughout the year, in support of accomplishing the strategic objectives of the organization. The communication process includes clarifying expectations, setting objectives, identifying goals, providing feedback, and reviewing results." In theory, a well-designed and documented performance management process can be rewarding for both managers and employees, however, in practice, it results in few unintended consequences such as, (1) performance management activities cost organizations a lot, (2) employees and even managers have come to despise the performance management requirements that their organizations impose and (3) the information gathered from these formal documentations often cannot be trusted. Although not always perfect, organizations are striving to constantly improve these processes for effective management of their full-time employees (Mueller-Hanson and Pulakos, 2018).

Despite the changing organizational attitude, the same approach, when applied to gig workers, is not able to fully justify their short-term performance management objectives. The effectiveness of the process is under question as they are people who usually prefer more flexibility and have high self-efficacy for pursuing tasks requiring more effort, setting higher goals and developing better strategies (Shane et al., 2003). In the present arrangement, in most cases, performance management in the gig economy is achieved by the setting of performance levels and using requester (demanding labour) feedback to rate gig worker performance (Meijerink and Keegan, 2019). Uber, Lyft and Deliveroo, for example, use a rating system which involves seeking feedback from customers on a star rating scale. In an organizational setting, performance-oriented managers have an ability to assess well but lack in providing effective rating and feedback, thus creating a disadvantage in monitoring the performance of gig workers (HBR, 2016). The limited relationship of the gig workers with their managers often accelerates these performance measuring factors to a result-based metrics.

Considering the above factors, competitiveness in the global economy is forging new links between the breadwinners, and these new links demand different and more flexible ways of managing performance. Provision of an equal opportunity for setting personalized business goals helps individuals in a blended team to focus on the business value while also seeking to recognize their own merit. An intuitive dashboard consisting of key performance indicators (KPIs), task completion percentages, behavioral competency ratings and real-time overall scoring can be created for the entire team, helping the manager to effectively monitor their performance. Short-term ratings can be provided to the individuals, thereby giving them scope to improve their performance in the subsequent assessment. Two-way feedback that incorporates real-time feedback mechanisms such as daily checkups, one-on-one performance discussions and addressing individual queries and grievances with the help of AI-driven chatbots should be promoted among the blended team. Thus, it is proposed that:

P2. A blended workforce PMS can support fairness by amalgamating the organized structure prevalent in the conventional PMS of full-time employees with the flexibility and agility pertinent to the gig workforce. 


\section{Learning and development}

In the 21st century globalized economy, human capital is the most crucial asset which differentiates a great organization from a good one, making the need for continuously updating the skills and knowledge of employees invaluable. The difference existing between the skills that the organizations want and skills their workforce offer have the potential to harm firm-level productivity and inflate the average labour costs as the workers are likely to be less productive in the presence of significant skill gaps, thus necessitating skill-gap training (McGuinness and Ortiz, 2015). Just-in-time learning is another form of learning which meets the rapidly changing needs by providing immediate training to the workers just before the requirement (Wilkie, 2013). For people having psychological inclination towards learning and growth, stretch assignments (any project or task given to employees that is beyond their current knowledge or skills level) act as accelerators of their development (Fiscor, 2018). Most companies enhance these learning methods by leveraging cross-functional workshops as a medium to deliver high level of product or service quality while also creating an environment of immediate career advancement (Chen and Tseng, 2012).

However, for gig workers, learning and development are often seen as their own responsibility and they do not enjoy the same levels of investment in their knowledge and skills as compared to full-time employees. Furthermore, they usually need to fund their own personal development to remain current in terms of skills and knowledge (Peel and Inkson, 2004). According to Kulkarni (2019), this gap is bridged with the help of new learning paradigms like e-learning, AI-based learning and microlearning which are available remotely and in flexible formats. The author states that the anytime and anywhere nature of the gig workforce helps them access e-learning modules on their own systems and devices which ranges from distance education to computerized electronic learning, Internet learning and many others. Also, bite-sized learning opportunities, in the form of digestible hour-long courses (microlearning), enable them to learn as per their needs and flexible work schedules (Kulkarni, 2019). For instance, Grab, a Southeast Asian ride-sharing platform, uses Axonify's microlearning platform to onboard, train and evaluate its drivers remotely on mobile devices instead of on site (Oesch, 2021). AI and machine learning-based systems further accelerates this shift by suggesting the right trainings to the right workers, providing them with the liberty to drive their own learning (Kulkarni, 2019).

The COVID-19 pandemic has been a catalyst for this transition and has resulted in organizations doubling up their efforts to provide a global digital learning platform to the emerging blended teams in organizations. Such an approach can help in delivering a holistic and seamless experience to the diverse individuals during the global crisis. The question which arises here is "how" one can meet the learning needs of this type of blended workforce. A simulation game designed to closely simulate the real-world management of blended workforce can attempt to answer this by training them on strategy, planning and other work-related tasks, thus providing an opportunity to explore various options to become future-ready. A centralized repository allowing the blended workers to access this simulation game along with various other course materials, documents and virtual sessions can be provided via multiple channels with proper data security measures in place. With the help of technology, these measures can be automatically customized in realtime based on their user profiles, transforming the entire learning and development system.

P3. The automatic customization of online learning in blended workforce can be achieved through a combination of skill alignment prevalent in L\&D programs of full-time employees and the existing digital assimilation in gig learning programs.
Gig economy in conventional workforce 
JWAM

13,2

\section{Rewards and recognition}

Rewards and recognition (R\&R) acts as a means of extra compensation for the workers to substantially contribute towards the organization and is directly linked with their overall development (Pardo del Val and Martî). Recognition when considered from an interactional perspective encompasses mutual benefit and takes human relationships into account (recognition-related interactions). The organizational level interactions, through different company policies and programmes, intend to recognize the work performed by the employees. On the one hand, vertical interactions between managers and employees intensify trustworthy relationships; on the other hand, horizontal interactions between peers and team members foster a sense of team spirit (Brun and Dugas, 2008). On-time bonuses translate these interaction types into meaningful recognition practices in the workplace increasing employee satisfaction and motivating them to perform better. The employees see their time and effort being rewarded, hence, improving their social life in the workplace (Anik et al., 2013).

By contrast, gig worker compensation equates to short-term, economic inducements in return for a specific contribution by the gig worker (Chen et al., 2015). In most cases, gig workers receive bonuses only when they exceed the organization's expectations by delivering high-quality performance. To ensure that gig workers live up to the requesters' expectations, intermediary platform firms may grant requesters the possibility to hold back payment from a gig worker when they feel gig worker performance is below par (Pavlou and Gefen, 2004). However, studies have shown that if organizations are willing to offer high bonuses, or other benefits, the gig workers may endeavor to reciprocate by providing high-quality work (Liu et al., 2020). Professional recommendations and endorsements are a by-product in the line of gig work when jobs are performed exceptionally well.

Such endorsements would also benefit the blended teams, soon to become a fad in the postCOVID-19 era. Our framework proposes a recognition portal to be featured as a center of excellence $(\mathrm{CoE})$ on the organization's main page which would exhibit various user profile links highlighting their exemplary work. This Wall of Fame will comprise of different individuals ranging from full-time employees to independent on-demand workers. These programmes can be aided with recognition ceremonies among co-workers by providing them with timely rewards and recognition such as orientation meetings for new joinees, on-time bonuses, personalized letters for life events, etc. The social component concerned with the relationship between the organization and these workers maybe expressed by recognizing the role and contribution of their professions towards the organizational society. Considering the above context, it is proposed that:

P4. A blended team will be more likely to perceive an exalted social merit by incorporating together the on-time recognition of full-time employees and the work quality-based benefits of gig workers.

\section{Career and succession planning}

Planning, being a future-oriented aspect, is important in every employee's life. While at the individual level, career planning predominantly analyses the employees' skills, abilities and interests to establish long-term goals, at the organizational level, succession planning analyses the key positions in an organization and the person required to fulfill that position. The studies by Schein $(1996 \mathrm{a}, \mathrm{b})$ show that most people have relatively stable career guidance termed as career anchors, which focuses on how talents, motives and values gradually combine into a career self-concept that determines career stability throughout their professional life. Although, major organizations promote a self-development approach to career management, it is always recommended that mentors discuss the career of employees considering two components: mentee's advancement in the organization and mentee's 
personal and professional growth via psycho-social support (Kidd et al., 2003). Job rotation is another key tool that employers use to help employees in internal mobility as well as succession planning for future organizational needs. Succession planning, a critical driver of organizational and leader restoration, generates a competitive pool of skilled people by offering uninterrupted services to enhance organizational productivity (Ali et al., 2019). To be complete and effective, succession planning templates (consisting of critical skill sets required for the leadership position, employees' current level of competency and possible future requirements) are created, continually reviewed and updated to reflect changes in the organization's operation.

Where the permanent employees are restricted by career boundaries within the organization, boundaryless career is the prevailing mode of gig economy, in terms of physical mobility and psychological mobility, making the gig workers responsible for their own career development (Kost et al., 2019). One of the main objectives of gig workers is an increase in their employability by pocketing additional gigs. Digitalization has directly impacted their employability by providing them with multiple opportunities to work globally. The global presence is however characterized by intra-organizational boundaries hindering their ability to work directly with clients or their upward movement within the organization (Kost et al., 2019).

A blended team can help reduce these intra-organizational boundaries by providing a uniform platform to both gig and full-time employees, where they can get specific updates related to new project openings within the organization. In the context of career planning, our research proposes SORT (skillset, openness, rise and trace) model where:

(1) Skillset represents the individuals' knowledge, skill, abilities and other characteristics (KSAOs) to meet the responsibilities of their current job.

(2) Openness denotes workers' flexibility in learning new skills for future requirements.

(3) Rise, refers to career growth which for a full-time employee might mean promotion, whereas for a gig worker, upgradation in terms of more pay or better project related tasks.

(4) Trace enables the organization to track the individuals' developmental goals for performance review, helping the workers to maintain excellent track record.

Therefore, it is proposed that:

P5. A blended workforce can positively drive an individual's career trajectory by enabling an environment of competence and diverse opportunities within the organization

Drawing on the above context, a futuristic approach of succession planning can be considered for a mix of young professionals working on a permanent or short-term basis. A Youth Leadership Program (YLP) is proposed to ensure a balanced approach in the postCOVID era. This program will be unique in the sense that highly skilled gig workers (identified through the SORT model) will be able to fill key leadership positions for the short term, helping organizations to minimize costs incurred from rigorous executive hiring. This program will also provide an opportunity to the young permanent workers to handle senior positions, acting as a top liaison between corporate operations and its shareholders and board of directors, providing them organizational exposure on a temporary basis. Considering this, it is further proposed that:

P6. Succession planning for a blended workforce will be more likely to enable equitable opportunities for proficient workers especially for leadership roles 
JWAM

13,2

\section{Person-organization fit}

The knowledge about organization's culture is crucial for its likelihood of success. Disregarding the impact of culture on an organization has proved to be one of the biggest obstacles when implementing change management (Cameron and Quinn, 2011). Our study tries to comprehend the person-organization fit by encapsulating the Competing Value Framework (CVF), which emphasizes on two dimensions to effectively explain the organizational climate: focus (internal or external processes) and stability (flexibility and control) (Quinn and Rohrbaugh, 1983). In conventional organizations, having a clearly defined Mission, Vision and Goal (MVG) statement helps employees develop a positive perception regarding their work. These statements drive the organizations to follow an internal process approach with one facet focused on increasing the efficiency of their full-time employees through clearly defined internal routines and communication channels, and the other facet guided by rules and work standards (Tong and Arvey, 2015).

The same approach fails to address the concerns of the gig workers, due to the short-term nature of their work and flexible non-standard forms of employment. This necessitates the use of technology to integrate the gig workers into the organization. Digital inclusion articulates their concerns related to opportunities, knowledge and skills by three broad facets: access (availability), adoption (digital literacy) and application (economic and workforce development), signifying the importance of digitally inclusive communities (Digital Inclusion Survey, 2013). The focus is characterized by differentiation through innovative ideas, external disruption and experimentation to build an organizational culture following an open system approach (Tong and Arvey, 2015).

These approaches are mutually exclusive, but can exist within the same organization in a blended team. Our research proposes a 3-Strike-fit technique which can be used to determine the change readiness of both full-time employees and gig workers:

(1) Accountability towards task and people.

(2) Long term association with the business.

(3) Pervasion till successful completion of work.

These elements ensure that the individual meshes with the organization's culture and is flexible in relation to the work environment. The post-COVID era will mark the beginning of a new social phenomenon involving numerous digital interactions with team members to learn more about them as human beings, for instance, asking them about their day or making them comfortable by mentioning little things like their pet, or the food they had. The diverse competencies in the blended team will help the organization approach any challenging situation with ease by customizing their unique skillset that they bring to the table. Thus, the following proposition is put forward:

P7. The composition of a blended workforce will be characterized by a culture that supports autonomy as well as control, and integration as well as differentiation.

Through the development of P1 to P7, the various facets of talent management cycle have been analysed, emphasizing the dire need of a blended workforce in the post-COVID era. In the new normal of reshaping talent and rethinking the future of work, our research proposes the COOKIE framework for a blended workforce, where the functions - collaboration, openness (person-organization fit), opportunity (career \& succession planning), knowledge (learning and development), incentives (rewards and recognition) and evaluation (performance management) presented in this paper are valuable to both organizations and the workforce in research as well as practice. The features of these talent management stages are illustrated in Figure 2. 


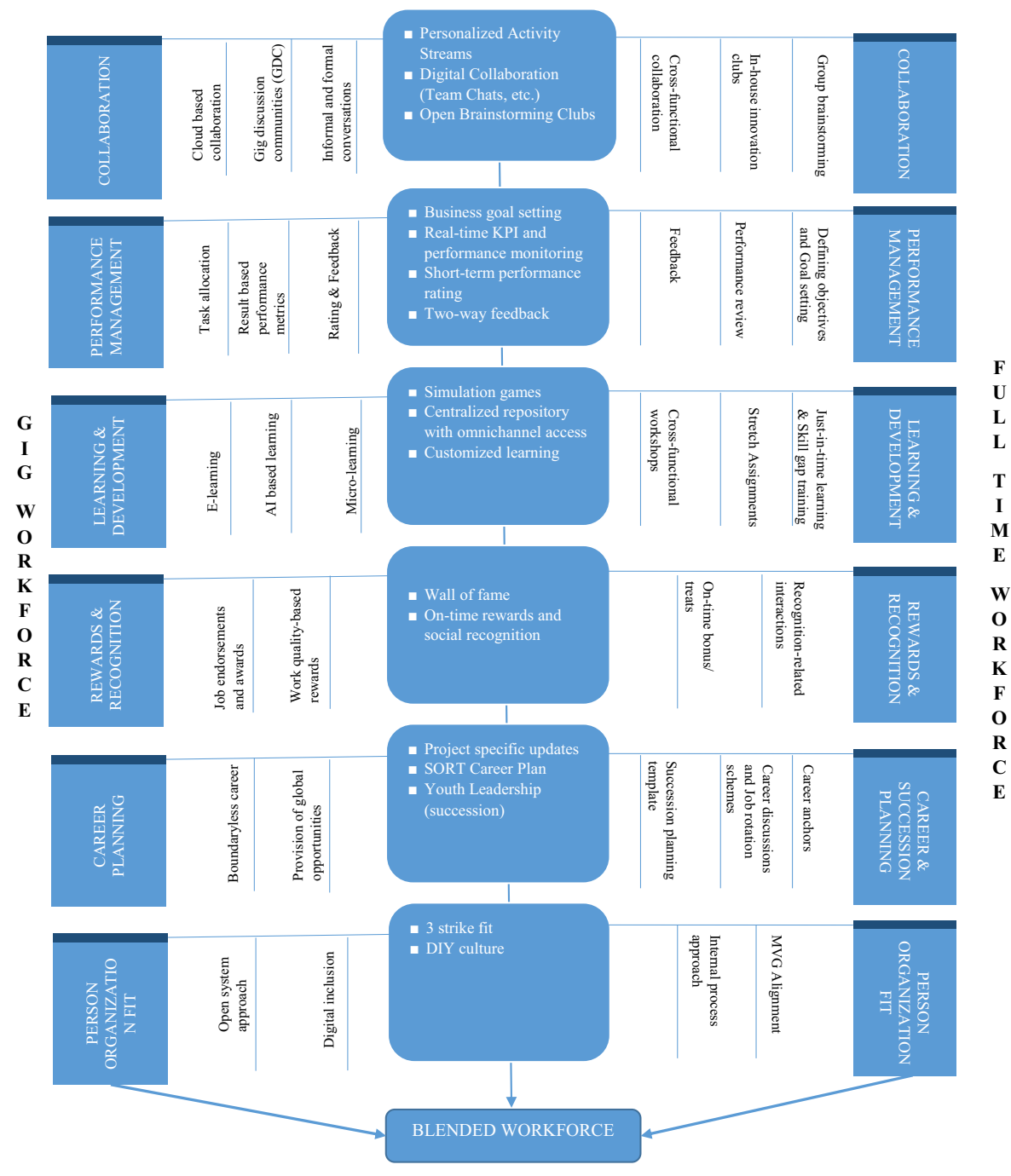

Gig economy in conventional workforce

Figure 2.

Different talent management stages and their features for the gig, permanent and blended workforce

\section{Limitations and implications}

Prior to discussing the theoretical and practical implications of this paper, three limitations must be addressed. First, due to lack of proper regulations in existing employment laws, the proposed conceptual framework does not consider potential exploitation of gig workers and the degree to which they should be mandated or be portable. Second, this paper does not incorporate the level of vulnerability to accidental disclosure and hacks related to data. Third, given the scope and timeframe of this research, the study does not ascertain the application of blended workforce framework across different sectors.

\section{Theoretical implications}

This research enriches the theoretical studies about the gig economy from the perspective of a blended workforce. While gig employment work provides more autonomy and allows 
JWAM

13,2

workers to concentrate on their own performance rather than other organizational commitments, technological advances allow the blended team to collaborate around the world and develop their skills by giving them a platform to deliver excellent performance on individual and team level (Paulas and Kenworthy, 2019; Elikwu, 2019; Ruggieri et al., 2016). The reward and recognition system set up by the organization further encourages and motivates the individuals. Moreover, the scope of equitable opportunities presented throughout the COOKIE framework strategically allows the organizations in achieving a fair balance among the gig workers and the full-time employees.

\section{Practical implications}

This study puts forward several managerial implications. The first pre-requisite to maintain effective collaboration in a blended workforce is to support social inclusivity by utilizing platforms and personalized activity streams within enterprise networking. Internal project managers and other professionals working in the blended team will play a crucial role in maintaining good relations between both parties. The second pre-requisite for enhancing employees' performance to the best of their abilities can be achieved by setting up a performance management system that focuses on realizing business value while also seeking to recognize individual merit. Managers will have to effectively monitor worker performance through intuitive dashboards with real-time key performance indicators (KPI), short-term performance ratings and feedback. The third pre-condition emphasizes on transforming the entire learning and development system for the blended team through real-world management simulation games, omnichannel accessible centralized repository, etc.

The fourth implication of our study suggests managers to learn how to effectively recognize the role and contribution of the blended team members towards the organizational society. Building a recognition portal and providing on-time rewards will boost employees' morale the fifth imperative deals with the context of career planning, wherein the proposed SORT (skillset, openness, rise and trace) model will help reduce intra-organizational career boundaries between gig and full-time workers. While on the other hand, in the context of succession planning, utilizing Youth Leadership Programme (YLP) will help top management bring in highly skilled gig workers to fill key leadership positions for the short term. Our study concludes with the final implication on person-organization fit, which is the most basic need of any individual or organization. Our proposed 3-Strike fit technique will help managers determine the change readiness of both full-time employees and gig workers to ensure whether the individual meshes with the organization's culture.

\section{Conclusion}

In this paper, we conceptually explored the need of a blended workforce in the post-COVID era, a movement from homogenous workforce to heterogenous workforce of full-time employees working in tandem with gig talents connected via digital platforms. By drawing on the concepts of various talent management functions, we developed propositions which predict that the alignment of the multilateral activities of the gig workers with permanent workforce will be leveraged in the future to address the needs of short-term specialized skills sets and scalable operations while creating a fair balance through a flexible and agile workforce. Considering its theoretical and practical importance, we hope that future research will continue to explore the various aspects of the framework essential to support the gig workers and the organizations. Finally, we encourage researchers to apply our taxonomy to derive insights on the societal influence of blended workforce within organizations and how it is likely to impact the behavior of gig workers and standard employees in the post-COVID era. 


\section{Notes}

1. Blended workforce is defined as a combination of permanent full-time staff and gig workers (such as part-time, temporary workers, contractors and freelancers) (Thompson and Mastracci, 2008, p. 364).

2. Hyper-personalization is defined as advanced and real-time customization of offerings, content, and customer experience at an individual level. (Capgemini Consulting and ESSEC, 2017, p. 5).

\section{References}

Abraham, K., Haltiwanger, J., Sandusky, K. and Spletzer, J. (2019), “The rise of the gig economy: fact or fiction?", AEA Papers and Proceedings, Vol. 109, pp. 357-361.

Ali, Z., Mahmood, B. and Mehreen, A. (2019), "Linking succession planning to employee performance: the mediating roles of career development and performance appraisal", Australian Journal of Career Development, Vol. 28 No. 2, pp. 112-121.

Anik, L., Aknin, L., Norton, M., Dunn, E. and Quoidbach, J. (2013), "Prosocial bonuses increase employee satisfaction and team performance", PLoS One, Vol. 8 No. 9, pp. 1-8.

Borino, F. (2018), "Piece rate pay and working conditions in the garment sector", p. 3, available at: https://www.ilo.org/wcmsp5/groups/public/—ed_dialogue/—dialogue/documents/publication/ wcms_663063.pdf (accessed 9 July 2020).

Brun, J. and Dugas, N. (2008), "An analysis of employee recognition: perspectives on human resources practices”, The International Journal of Human Resource Management, Vol. 19 No. 4, pp. 716-730.

Brunelli, L.M. (2019), What Is a Per-Piece Pay Rate or Piecework?, The Balance Careers, available at: https://www.thebalancecareers.com/what-is-per-piece-work-3542479 (accessed 9 July 2020).

Cameron, K.S. and Quinn, R.E. (2011), Diagnosing and Changing Organizational culture:Based on the Competing Values Framework, John Wiley \& Sons, New York, NY.

Capgemini Consulting and ESSEC (2017), Hyper-personalization vs. Segmentation: has Big Data made Customer Segmentation Redundant?, p. 5, available at: https://www.capgemini.com/consultingfr/wp-content/uploads/sites/31/2017/08/hyperpersonnalisation_vs_segmentation_english_0501-2017.pdf (accessed 9 July 2020).

Chappe, R.L. and Jaramillo, C. (2020), "Artisans and designers: seeking fairness within capitalism and the gig economy”, $D E A R Q$, Vol. 26, pp. 80-87.

Chen, L. and Tseng, C. (2012), "Benefits of cross-functional training: three departments of hotel line supervisors in Taiwan", Journal of Hospitality and Tourism Management, Vol. 19 No. 1, pp. 115-122.

Chen, L., Mislove, A. and Wilson, C. (2015), "Peeking beneath the hood of Uber", Proceedings of the 2015 Internet Measurement Conference, ACM.

Digital Inclusion Survey (2013), What is Digital Inclusion?, available at: https://digitalinclusion.umd. edu/content/what-digital-inclusion (accessed 23 July 2020).

Elikwu, F. (2019), "Exploring the impact of cross-functional collaboration on organizational mission alignment", SSRN Electronic Journal. doi: 10.2139/ssrn.3396876.

EY (2020), COVID-19 and Pandemic Planning: How Companies Should Respond, available at: https:// www.ey.com/en_in/covid-19/covid-19-and-pandemic-planning-how-companies-should-respond (accessed 18 July 2020).

Financial Express (2020), "TCS 'work from home' policy: only one-fourth of workers to come to office; CEO explains Vision $25 \times 25$ ”, 27 May, available at: https://www.financialexpress.com/industry/ tcs-work-from-home-policy-only-one-fourth-of-workers-to-come-to-office-ceo-explains-vision25x25/1971995/ (accessed 18 July 2020).

Fiscor, S. (2018), "The stretch assignment: Engineering, geology, mineralogy, metallurgy, chemistry, etc", Engineering and Mining Journal, Vol. 219 No. 6, p. 2, available at: https://search.proquest. com/docview/2061463738?accountid=38934 (accessed 20 July 2020).

Gig economy in conventional workforce 
JWAM

13,2

Harvard Business Review (2016), Performance Management in the Gig Economy, [online] available at: https:/hbr.org/2016/01/performance-management-in-the-gig-economy (accessed 19 July 2020).

Healy, J., Nicholson, D. and Pekarek, A. (2017), "Should we take the gig economy seriously?", Labour and Industry: A Journal of the Social and Economic Relations of Work, Vol. 27 No. 3, pp. 232-248.

Hyman, L. (2018), Temp, Viking, New York, NY.

Jabagi, N., Croteau, A., Audebrand, L. and Marsan, J. (2019), "Gig-workers' motivation: thinking beyond carrots and sticks", Journal of Managerial Psychology, Vol. 34 No. 4, pp. 192-213.

Johnes, G. (2019), "The gig economy in the UK: a regional perspective", Journal of Global Responsibility, Vol. 10 No. 3, pp. 197-210.

Kidd, J., Jackson, C. and Hirsh, W. (2003), "The outcomes of effective career discussion at work", Journal of Vocational Behavior, Vol. 62 No. 1, pp. 119-133.

Knowledge@Wharton (2020), Planning for the Post-COVID-19 Workforce: Four Scenarios, available at: https://knowledge.wharton.upenn.edu/article/planning-post-covid-19-workforce-fourscenarios/ (accessed 2 July 2020).

Kost, D., Fieseler, C. and Wong, S. (2019), "Boundaryless careers in the gig economy: an oxymoron?”, Human Resource Management Journal, Vol. 30 No. 1, pp. 100-113.

Kulkarni, R. (2019), Training for the Gig Gconomy- the L\&D Way, People Matters, available at: https:// www.peoplematters.in/article/training-development/training-for-the-gig-Peconomy-the-ld-way23904 (accessed 20 July 2020).

Liu, W., He, C., Jiang, Y., Ji, R. and Zhai, X. (2020), "Effect of gig workers' psychological contract fulfillment on their task performance in a sharing economy - a perspective from the mediation of organizational identification and the moderation of length of service", International Journal of Environmental Research and Public Health, Vol. 17 No. 7, pp. 1-20.

McGuinness, S. and Ortiz, L. (2015), Skill Gaps in the Workplace: Measurement, Determinants and Impacts, IZA Discussion Papers, No. 9278, Institute for the Study of Labor (IZA), Bonn, available at: http://hdl.handle.net/10419/114146 (accessed 20 July 2020).

Meijerink, J. and Keegan, A. (2019), "Conceptualizing human resource management in the gig economy”, Journal of Managerial Psychology, Vol. 34 No. 4, pp. 214-232.

Morrison-Smith, S. and Ruiz, J. (2020), "Challenges and barriers in virtual teams: a literature review", SN Applied Sciences, Vol. 2 No. 1096, pp. 1-33.

Mueller-Hanson, R. and Pulakos, E. (2018), Transforming Performance Management to Drive Performance: An Evidence-Based Roadmap (1e), Routledge, New York, NY.

Nkengasong, J. and Mankoula, W. (2020), "Looming threat of COVID-19 infection in Africa: act collectively, and fast”, The Lancet, Vol. 395 No. 10227, pp. 841-842.

Oesch, T. (2021), Training and Managing the Gig Workforce - Training Industry, Training Industry, available at: https://rainingindustry.com/articles/workforce-development/training-andmanaging-the-gig-workforce/ (accessed 15 May 2021).

Pardo del Val, M. and Martínez Fuentes, C. (2003), "Resistance to change: a literature review and empirical study", Management Decision, Vol. 41 No. 2, pp. 148-155.

Paulas, P.B. and Kenworthy, J.B. (2019), "Effective brainstorming", Paulas, P.B. and Nijstad, B.A. (Eds), The Oxford Handbook of Group Creativity and Innovation, Oxford University Press, New York, NY, pp. 287-305.

Pavlou, P.A. and Gefen, D. (2004), "Building effective online marketplaces with institution-based trust", Information Systems Research, Vol. 15 No. 1, pp. 37-59.

Peel, S. and Inkson, K. (2004), "Contracting and careers: choosing between self and organizational employment”, Career Development International, Vol. 9 No. 6, pp. 542-558.

Quinn, R.E. and Rohrbaugh, J. (1983), “A spatial model of effectiveness criteria: towards a competing values approach to organizational analysis", Management Science, Vol. 29 No. 3, pp. 363-377. 
Reddy, C. (2016), Piece Rate Pay: Definition, Advantages and Disadvantages, WiseStep, available at: https://content.wisestep.com/advantages-disadvantages-piece-rate-pay/ (accessed 9 July 2020).

Ruggieri, A., Mosconi, E., Poponi, S. and Silvestri, C. (2016), "Digital innovation in the job market: An explorative study on cloud working platforms", in Torre, T., Braccini, A.M. and Spinelli, R. (Eds), Empowering organizations, Lecture Notes in Information Systems and Organisation, Springer, Cham, Switzerland, Vol. 11, pp. 273-283, doi: 10.1007/978-3-319-23784-8_21.

Savarimuthu, A. and Rachel, J.A. (2017), "Psychological contract - a conceptual framework"”, International Journal of Management, Vol. 8 No. 5, pp. 101-110.

Scheiber, N. (2017), "How uber uses psychological tricks to push its drivers' buttons", The New York Times, 2 April, available at: https://nyti.ms/2nMmDtc (accessed 9 July 2020).

Schein, E.H. (1996a), "Career anchors revisited: implications for career development in the 21st century", The Academy of Management Executive, Vol. 10 No. 4, pp. 80-88.

Schein, E.H. (1996b), Identidade profissional: Como ajustar suas inclinações a suas opções de trabalho, Editora Nobel, São Paulo, SP.

Shane, S., Locke, E.A. and Collins, C.J. (2003), "Entrepreneurial motivation", Human Resource Management Review, Vol. 13 No. 2, pp. 257-279.

SIA (2018), "The human cloud, the gig economy and the transformation of work", pp. 3-5, available at: https://www2.staffingindustry.com/content/download/266526/9732110/2018_GigEconomy_ Summary_Web_1810.pdf (accessed 9 July 2020).

Stanford, J. (2017), "The resurgence of gig work: historical and theoretical perspectives", The Economic and Labour Relations Review, Vol. 28 No. 3, pp. 382-401.

Stewart, A. and Stanford, J. (2017), "Regulating work in the gig economy: what are the options?", The Economic and Labour Relations Review, Vol. 28 No. 3, pp. 420-437.

Tanski-Phillips, M. (2018), What is Piecework?, Patriot, available at: https://www.patriotsoftware.com/ blog/payroll/piecework-pay/ (accessed 9 July 2020).

Thompson, J. and Mastracci, S. (2008), "The blended workforce: alternative federal models", Public Personnel Management, Vol. 37 No. 3, pp. 363-380.

Tong, Y.K. and Arvey, R.D. (2015), "Managing complexity via the competing values framework", Journal of Management Development, Vol. 34 No. 6, pp. 653-673.

UC Berkeley HR (2020), "Performance management: concepts and definitions | people and culture", available at: https://hr.berkeley.edu/hr-network/central-guide-managing-hr/managing-hr/ managing-successfully/performance-management/concepts (accessed 19 July 2020).

Whitehead, G.P. (2019), The History and Future of the Gig Economy, Small Business Trends, available at: https://smallbiztrends.com/2019/11/the-history-and-future-of-the-gig-economy.html (accessed 2 July 2020).

Wilkie, B. (2013), An Assessment of a Just-in-Time Training Intervention in a Manufacturing Organization, Ph.D. Dissertation, No. 31, University of Southern Mississippi, Mississippi, available at: https://aquila.usm.edu/dissertations/31 (accessed 20 July 2020).

\section{Further reading}

Brown, T. (2020), "The gig economy", Daily Beast, 12 January, available at: https://www.thedailybeast. com/the-gig-economy (accessed 9 July 2020).

Conway, N. and Briner, R. (2002), "Full-time versus part-time employees: understanding the links between work status, the psychological contract, and attitudes", Journal of Vocational Behavior, Vol. 61 No. 2, pp. 279-301. 
JWAM

13,2

About the authors

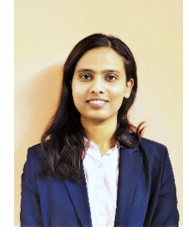

Manjari Mahato is PGP HRM from Xavier School of Human Resource Management, Xavier University Bhubaneswar, India. She interned with Tata Steel Ltd. on the project titled "Development of Technical Competency Framework for Officers in the Agglomerates Cluster" in the year 2020 for her Summer Internship Project. She has 21 months of work experience as a Senior Analyst, SAP BW Developer, in Capgemini, India. She did her Bachelor of Technology in Electronics and Communication Engineering from RCC Institute of Information Technology, Kolkata. She aspires to become a visionary figure in the field of People Strategy. She is one of the co-founders of an HR weekly publication by the name "People Bound" started in July 2020.

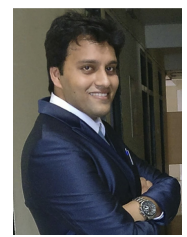

Nitish Kumar is PGP HRM from Xavier School of Human Resource Management, Xavier University Bhubaneswar, India. He interned with Tata Steel Ltd. on the project titled "Action Plan on Employee Engagement in Shared Services" in the year 2020 for his Summer Internship Project. He has 33 months of work experience as a Test Engineer, in Infosys Limited, India. He did his Bachelor of Engineering in Biotechnology from Birla Institute of Technology, Mesra, Ranchi. He is one of the co-founders of an HR weekly publication by the name "People Bound" started in July 2020. He aspires to be the CHRO or HR Director of his own company.

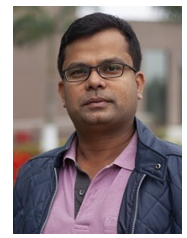

Lalatendu Kesari Jena is an Assistant Professor (Human resources) in Xavier School of Human Resource Management, Xavier University, Bhubaneswar, India. He has more than 19 years of experience in both academics and corporate HR (with Hindustan Aeronautics Limited, Indian Defence PSU), including seven years as Faculty Member in $\mathrm{HR}$ at ICFAI University, Hyderabad, India and Central University of Orissa, India. He specializes in the areas of human resource planning, performance management, learning and development, and talent assessment. His research interest lies in areas such as HRM and Sustainable Development Goals; Self-steering, self-Organizing Teams and Leadership ; Job Crafting; Job Insecurity; Millennial's and work ethics ; Return on Investment in HR Programs ; Sustainable HR through Disruptive Leadership ; Attitude and Productivity ; Joy at Work ; Workplace Persuasion ; Employee Retention and Leadership Challenges ; Abusive Supervision ; Performance in Multi-tasking Environment; Stress and Coping ; Meaningful Engagement and he has published papers on them in tiered national and international journals. He has completed his Ph.D. from IIT Kharagpur, India, on the topic "Workplace Spirituality and Human Resource Effectiveness" and is pursuing Post Doc. on "Employee Retention and Leadership Challenges" at Loyola Leadership School, Universidad Loyola, Seville, Spain. A passionate trainer, Prof. L K has conducted several corporate training sessions and leadership workshops for organizations across diverse industries. Lalatendu Kesari Jena is the corresponding author and can be contacted at: 1kjena@xub.edu.in

For instructions on how to order reprints of this article, please visit our website:

www.emeraldgrouppublishing.com/licensing/reprints.htm

Or contact us for further details: permissions@emeraldinsight.com 